\title{
Management of bone metastases in refractory prostate cancer - role of denosumab
}

This article was published in the following Dove Press journal:

Clinical Interventions in Aging

14 September 2012

Number of times this article has been viewed

\author{
Channing J Paller' \\ Michael A Carducci' \\ George K Philips ${ }^{2}$ \\ 'Sidney Kimmel Comprehensive \\ Cancer Center at Johns Hopkins, \\ Baltimore, MD, USA; ${ }^{2}$ Georgetown \\ Lombardi Comprehensive Cancer \\ Center, Washington DC, USA
}

Correspondence: Channing Paller Sidney Kimmel Comprehensive Cancer Center, Johns Hopkins Hospital, I650 Orleans Street, Room IM59, Baltimore, MD 21 287, USA

Tel + I 4I 09558239

Email cpaller I@jhmi.edu

\begin{abstract}
This article reviews the problem of bone disease in prostate cancer and the evolving role of the novel agent denosumab, a fully human monoclonal antibody that inhibits the receptor activator of nuclear factor- $\mathrm{\kappa B}$ ligand, in suppressing bone resorption and offering bone protection in this disease. Prostate cancer frequently metastasizes to bone, and additionally its treatment with androgen deprivation leads to accelerated bone loss resulting in clinically relevant skeletal complications associated with disabling symptoms. Among the bone-targeting therapeutic strategies investigated for the prevention of bone complications, the potent bisphosphonate zoledronic acid has been the most widely used agent for bone protection in the past decade. Denosumab is the first among a new class of osteoclast-targeting agents to show superior efficacy in several clinical scenarios in both prostate and breast cancer, as well as in osteoporosis, but the focus of this review will be on its role in prostate cancer. The safety and efficacy of denosumab versus zoledronic acid was established in a randomized trial, demonstrating a delay in skeletal-related events in metastatic castration-resistant prostate cancer patients. This study led to the approval of denosumab in the US. The chief risks of denosumab were hypocalcemia and osteonecrosis of the jaw. Denosumab was also approved for fracture risk reduction in patients on androgendeprivation therapy for nonmetastatic prostate cancer. Although denosumab extended bone metastasis-free survival in a Phase III trial in men with castration-resistant nonmetastatic prostate cancer to a statistically significant degree, a Food and Drug Administration committee found that the effect was not sufficiently clinically meaningful for regulatory approval, and the Food and Drug Administration issued a letter concurring with the committee's recommendation. The role of denosumab in prostate cancer will continue to evolve either as monotherapy or in combination with other bone-targeting strategies.
\end{abstract}

Keywords: denosumab, prostate cancer, bone disease

\section{Introduction to bone disease in prostate cancer Epidemiology}

Globally, 903,500 new cases of prostate cancer were estimated to have occured in 2011, second only to lung cancer in men, and 258,400 deaths from prostate cancer were estimated for 2011. ${ }^{1}$ In the United States, 241,740 new cases of prostate cancer and 28,170 prostate cancer deaths are estimated to occur in $2012 .^{2}$ Older age, black race, and family history are the most consistent risk factors for prostate cancer. The majority of patients with localized early stage disease do not develop metastases and do not die of prostate cancer. However, among patients with castration-resistant metastatic prostate cancer, over $80 \%$ of patients have bone metastases, which is the most common site of metastases in this group. ${ }^{3,4}$ The distribution of bone metastases favors the axial skeleton (pelvic bone, 
spine, and ribs) over the appendicular skeleton (long bones), although proximal femoral metastases are common.

\section{Clinical presentation}

Advanced prostate cancer comprises a series of states along a continuum of disease progression depending on whether serum androgen levels are in the castrate range or not, and whether clinical metastases are present versus only a rising prostate-specific antigen (PSA). To a lesser extent, the clinical state depends on whether first line chemotherapy has been received, and whether patients have become symptomatic. The most common intervention for recurrent or advanced prostate cancer is surgical or medical castration (androgen deprivation or testosterone suppressive therapy). Based on clinical trial endpoints proposed by the Prostate Cancer Working Group 2, a clinical states model has emerged to guide clinical practice for castration-resistant prostate cancer (CRPC) (Table 1). ${ }^{5}$

In nonmetastatic CRPC with progression manifested only by a rising PSA, the objective is to delay or prevent metastases which are associated with morbidity. ${ }^{9-11}$ These patients have a bone metastasis-free survival exceeding 2 years, an endpoint that is associated with baseline PSA and PSA velocity. ${ }^{9,10}$ In metastatic CRPC, the principal goals are to prevent skeletal-related complications of metastases, including the need for surgical or radiotherapeutic interventions, as well as to improve patient reported outcomes such as bone pain and health-related quality of life.

Patients with bone metastases may be symptomatic or asymptomatic when osseous lesions are found on imaging studies either at initial staging or in response to a rising PSA after treatment. The most prevalent symptom of bony metastases is bone pain, but a variety of catastrophic complications

Table I Prostate cancer clinical states model for metastatic, castration-resistant prostate cancer

\begin{tabular}{lll}
\hline State & $\begin{array}{l}\text { Recently approved } \\
\text { treatments }\end{array}$ & $\begin{array}{l}\text { Positive phase III } \\
\text { trial results }\end{array}$ \\
\hline $\begin{array}{l}\text { Rising PSA: } \\
\text { castration-resistant }\end{array}$ & None & None \\
$\begin{array}{l}\text { Metastatic castration- } \\
\text { resistant Ist line } \\
\text { therapy }\end{array}$ & $\begin{array}{l}\text { Docetaxel, } \\
\text { sipuleucel-T, } \\
\text { zoledronic acid, }{ }^{* * *} \\
\text { denosumab** } \\
\text { Metastatic castration- } \\
\text { resistant post-docetaxel }\end{array}$ & $\begin{array}{l}\text { Abiraterone, } \\
\text { alpharadin }^{7 *}\end{array}$ \\
& $\begin{array}{l}\text { abiraterone, } \\
\text { zoledronic acid, }{ }^{* *} \\
\text { denosumab** }\end{array}$ & Enzalutamide, $^{8 *}$ \\
\hline
\end{tabular}

Notes: *Patients who refused or were ineligible for docetaxel; **approved treatment of patients with documented bone metastases, not for survival.

Abbreviation: PSA, prostate-specific antigen. can occur including pathologic fracture, spinal cord compression, radiculopathy, and cauda equina syndrome. Uncommonly, extensive bone marrow infiltration and displacement of normal hematopoiesis may lead to cytopenias. However, hypercalcemia is rare. Not infrequently, radiation or surgical approaches (with their own attendant morbidities) are required to prevent impending complications such as epidural cord compression and pathologic fracture; hence, the need for such treatment is frequently a component of the composite endpoint for skeletal-related complications in clinical trials targeting bone metastases. ${ }^{12}$

In evaluating metastatic bone disease, plain radiographs and computerized tomography scans show a predominantly blastic (or "sclerotic") pattern of osseous metastases, but increases in serum markers of bone resorption testify to accelerated osteolytic activity even without histologic findings of increased osteoclasts. ${ }^{13}$ Magnetic resonance imaging has a relatively superior ability to identify soft tissue and marrow components of bone metastases. ${ }^{14}$ Use of 18 -fluoride positron emission tomography-computerized tomography scans has expanded due to the superior accuracy for detection of bone metastases over planar bone scintigraphy, but its role in the management of prostate cancer is currently under active review. ${ }^{15}$

\section{Pathophysiology}

Normal bone homeostasis involves constant bone remodeling balanced by osteoblastic and osteolytic processes in a coordinated manner, which results in the stability, integrity, and strength of adult bone. Osteoclasts are derived from the macrophage lineage and are activated at the bone surface by cytokines and hormones in the bone microenvironment to resorb bone. ${ }^{13}$ Osteoclasts create a resorption vacuole at the bone surface into which proteases are released that dissolve the bone matrix. ${ }^{16}$ Osteoblasts are derived from mesenchymal stem cells and are involved in bone formation, but interact with osteoclasts and a variety of molecules in concert, and eventually evolve into mature osteocytes.

A key molecule in the bone microenvironment, receptor activator of nuclear factor- $\kappa \mathrm{B}$ (RANK), is expressed by osteoclasts, and plays an integral role in osteoclast development and apoptosis. RANK is activated by RANK ligand (RANKL), a member of the tumor necrosis factor family, which is in turn expressed by bone marrow stromal cells and osteoblasts. The binding of RANKL to RANK leads to osteoclast differentiation and activation; RANKL inhibition modulates the bone microenvironment by inhibiting osteoclast-mediated bone destruction. ${ }^{12}$ Osteoblasts and 
stromal cells maintain physiologic balance by also producing osteoprotegerin, which stimulates osteoclasts to induce apoptosis by acting as a decoy for RANKL and preventing the binding of RANKL to RANK. In metastatic prostate cancer, bone structure is disordered and bone strength is suboptimal because prostate cancer cells create an imbalance in the normal osteoprotegerin to RANKL ratio essential for the maintenance of normal bone remodeling.

The blastic metastases are associated with increased markers of bone resorption such as urinary $\mathrm{N}$-telopeptide (uNTX) and C-terminal peptide fragments of type 1 collagen, indicating that osteoclast activity is also increased. Baseline uNTX was a stronger predictor of skeletal metastatic complications than was bone-specific alkaline phosphatase in prostate and other solid tumors, which is strongly suggestive of a clinically relevant degree of osteolytic activity. ${ }^{17}$ Markers of bone resorption are further elevated upon institution of androgen deprivation therapy (ADT), and the impact of antiresorptive strategies on both lowering the levels of these markers as well as reducing the frequency of clinical skeletal endpoints further supports the crucial role of osteolysis in the development of skeletal morbidity. ${ }^{11,18}$

\section{Prostate cancer therapy-induced osteoporosis}

The concept of hormone-manipulation-induced bone loss in men is supported by multiple lines of evidence. Bone mineral density in men depends on both estrogen and testosterone levels, a finding supported by epidemiological studies, human experiments of the nature of males born with aromatase deficiency, as well as by controlled intervention studies. ${ }^{19,20}$ ADT for prostate cancer leads to accelerated bone loss at a rate of approximately $2 \%-4 \%$ per year despite calcium and vitamin D supplementation. ${ }^{21}$

The consequences of androgen-deprivation-mediated bone loss include fragility fractures, most consequentially at vertebral and hip sites, leading to pain, disability, hospitalization, and excess mortality. In a SEER-Medicare linked database analysis, the use of androgen deprivation nearly doubled the risk of fractures over a 5-year period. ${ }^{22}$ Factors associated with fragility fractures were examined in 1244 men with androgen deprivation, who were participating in a prospective clinical trial of fracture prevention. The factors included white race and the presence of osteoporosis, but not age, testosterone levels, estradiol levels, or markers of bone turnover. ${ }^{23}$ Analysis of linked administrative databases in Canada of 19,079 men with prostate cancer who had received at least 6 months of androgen deprivation followed for a mean of 6.5 years versus men who had never received androgen deprivation, confirmed an increased hazard ratio (HR) of 1.65 for fragility fractures. ${ }^{24}$

\section{Overview of current bone-targeting strategies for castration-resistant prostate cancer}

A set of strategies for bone protection has been investigated and deployed in recent years, most commonly for more advanced or refractory stages of prostate cancer on which this review will focus. It should be noted, however, that in the past decade, there has been more frequent use of adjuvant androgen therapy in association with radiation for intermediate and high risk, clinically-localized prostate cancer based on demonstrated survival benefits. ${ }^{25-27}$ Furthermore, many patients who develop biochemical failure (rising PSA as sole evidence of disease recurrence) after definitive local therapy are treated for long durations with ADT.

Many systemic antiprostate cancer therapies such as chemotherapy and hormonal therapy have been shown to reduce bone complications or improve health-related quality of life. ${ }^{28,29}$ Additionally, systemic agents with selectivity for antineoplastic effects at the site of bone metastases have been tested or are under development for effects on palliation or survival in the setting of castration-resistant metastatic disease. These agents include, but are not limited to, endothelin receptor antagonists such as atrasentan, ${ }^{30}$ zibotentan, ${ }^{31}$ Src kinase inhibitors, ${ }^{32}$ and radiopharmaceuticals such as strontium-89 and samarium-153, ${ }^{33}$ and more recently, alpharadin (radium-223).

Until recently the most widely used evidence-based bone-targeting agents were in the bisphosphonate class. In the past 2 decades, bisphosphonates became the most commonly used osteoclast-inhibiting class of agents among cancer patients utilized for humoral hypercalcemia, bone loss, and bone metastasis. A first-generation bisphosphonate (clodronate) was tested in its oral form in the 1990s by the UK Medical Research Council in two studies against placebo in adjuvant (trial PR04) and metastatic (trial PR05) prostate cancer settings for the end points of bone metastasis-free survival and bone progression-free survival. Although the initial results were negative, there was a suggestion of a survival benefit in the PR05 trial with longer follow up. ${ }^{34}$ Weekly oral alendronate, quarterly intravenous pamidronate, and annual intravenous zoledronic acid have each been shown to reduce bone loss and improve bone density, but not reduce fracture risk, in men receiving androgen deprivation. ${ }^{21,35,36}$ Intravenous pamidronate every 3 weeks did not reduce 
any bone pain measure or skeletal-related complications in prostate cancer patients with metastatic bone pain, though bone turnover markers were suppressed. ${ }^{37}$ In men with castration-resistant prostate cancer metastatic to bone, the highly potent bisphosphonate (zoledronic acid) was the first bisphosphonate to achieve a decrease in the composite end point of skeletal-related events (SREs). These SREs were comprised of pathologic fractures, spinal cord compression, surgery, or radiation to bone, or change of antineoplastic therapy to treat bone pain, leading to its approval in the United States. ${ }^{38}$ It rapidly became the standard of care and the comparator for testing future bone-targeting agents in this setting. Recently, a human monoclonal antibody against RANKL (denosumab) has emerged as an alternative treatment. The efficacy and risks of denosumab are the focus of the remainder of this review.

\section{Review of the pharmacology and pharmacokinetics of denosumab}

Denosumab suppresses osteoclast formation in humans by binding to RANKL, which in turn inhibits RANK activation; immunoassays showed denosumab to be specific for human RANKL. ${ }^{39}$

The mechanism of action of denosumab in bone is displayed in Figure 1. Of note, after up to 3 years of treatment, no patients developed denosumab-neutralizing antibodies. ${ }^{40}$ Subcutaneous denosumab treatment in patients with prostate cancer-related metastases resulted in decreased bone turnover in a Phase II trial ${ }^{41}$ and a Phase III trial. ${ }^{12,42}$

\section{Bone density, microarchitecture, and mineralization effects of denosumab}

In murine models, denosumab improved bone density and bone volume and reduced bone resorption. ${ }^{39}$ These preclinical findings were confirmed in humans in a Phase II placebo controlled study of subcutaneous denosumab versus oral alendronate in post-menopausal women with severe osteopenia or osteoporosis ( $\mathrm{T}$ score between -2.0 and -3.0). Significant increases were seen at 12 months, in distal radial total, cortical, and trabecular volumetric bone mineral density in denosumab-treated patients versus placebo. Increases in volumetric bone mineral density at the radius and density-weighted polar moment of inertia, an indicator of bone strength, were significantly greater in denosumab-treated patients versus placebo $(P<0.001)$ and versus alendronate-treated $(P<0.05)$ patients at 6 and 12 months. $^{44}$

\section{Biomarkers of bone turnover}

Biochemical markers of bone resorption provide clinically useful evidence of pathological bone cell activity and may aid in the management of patients with skeletal disorders. Denosumab treatment in clinical trials showed sustained reductions from baseline levels of multiple biomarkers of bone resorption and bone formation. ${ }^{12,41,42,45-47}$ These biomarkers provide evidence for the efficacy of therapies and their prognostic value; elevation of these biomarkers is generally correlated with SREs, disease progression, and death in patients with bone metastases. ${ }^{48}$

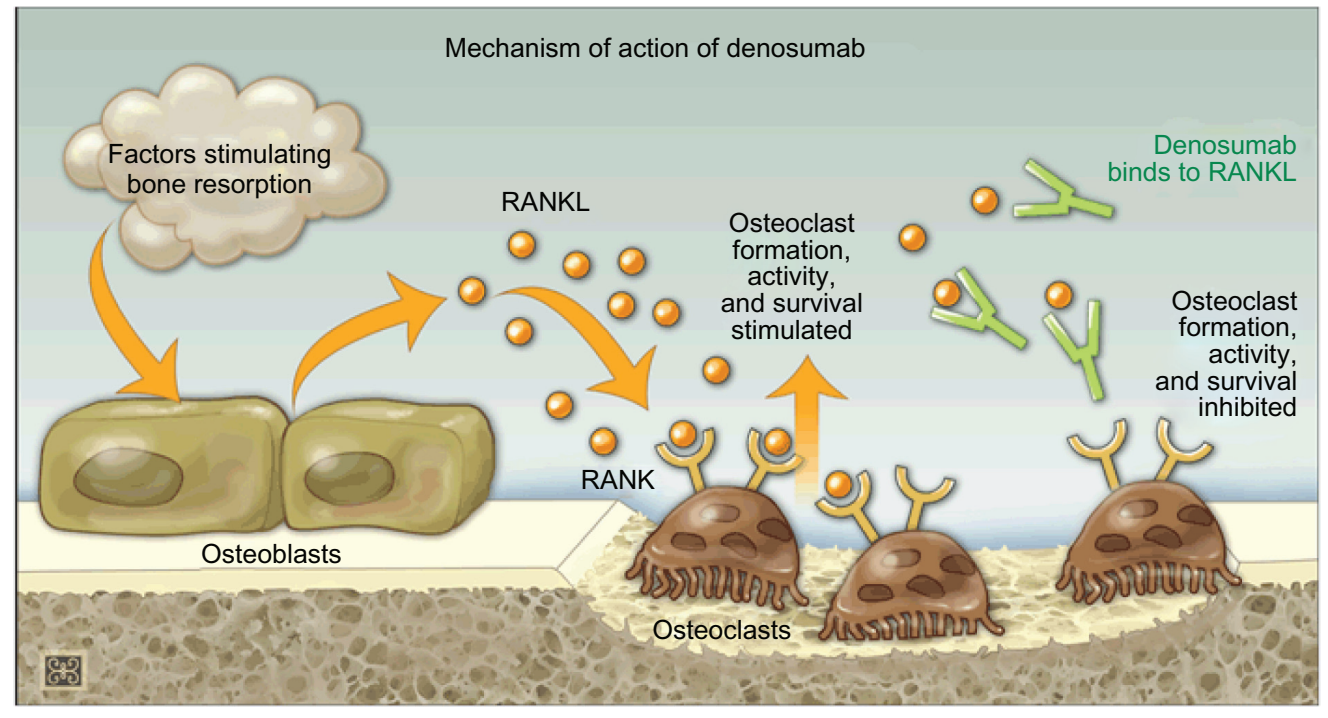

Figure I Mechanism of action of denosumab.

Note: Copyright $(\mathrm{C}$ 2012. Nature Publishing Group. Reproduced with permission from Lewiecki EM, Bilezikian JP. Denosumab for the treatment of osteoporosis and cancerrelated conditions. Clin Pharmacol Ther. 2012;91(1):123-133.43

Abbreviations: RANKL, receptor activator of nuclear factor- $\mathrm{KB}$ legends; RANK, receptor activator of nuclear factor- $\mathrm{KB}$. 
Over the course of 2 to 13 weeks, rapid, sustained reductions in levels of uNTX corrected for creatinine (uNTX/ $\mathrm{Cr}$ ) were seen in patients receiving denosumab every 4 weeks. The suppression levels were maintained through 25 weeks of treatment. ${ }^{41,49}$ After 13 weeks, 73\%-84\% reductions from baseline in $\mathrm{uNTX} / \mathrm{Cr}$ were reported for both bisphosphonate treatment-naïve and bisphosphonate treatment-experienced patients. ${ }^{12,42,45,46}$ Furthermore, pharmacokinetic/pharmacodynamic modeling of the data from one study provided a prediction of more than $90 \%$ uNTX/Cr suppression in $95 \%$ of patients on $120 \mathrm{mg}$ of denosumab given once every 4 weeks, with no substantial increase in suppression for higher doses. ${ }^{46}$

\section{Pharmacokinetics of denosumab}

Denosumab reaches maximum serum concentrations at 10 days (range 3-21 days) following a single $60 \mathrm{mg}$ subcutaneous dose in healthy volunteers $(\mathrm{n}=73)$; mean maximum serum concentration was $6.75 \mathrm{mg} / \mathrm{mL} .{ }^{50}$ Dose proportional increases in exposure were observed at denosumab doses above $60 \mathrm{mg}$, though lower dose levels exhibited nonlinear pharmacokinetic properties. ${ }^{51}$ Denosumab is absorbed rapidly, with detectable serum concentrations of $>1$ and $>5 \mu \mathrm{g} / \mathrm{mL}$ observed 1 hour after a single subcutaneous dose of 1.0 to $3.0 \mathrm{mg} / \mathrm{kg}$, respectively. The levels were sustained throughout the 84-day period of observation. Steady state serum levels of $20.5 \mu \mathrm{g} / \mathrm{mL}$ were reached by 6 months following multiple $120 \mathrm{mg}$ subcutaneous doses administered every 4 weeks. $^{47}$

Denosumab pharmacokinetics are not affected by renal impairment even when patients are on hemodialysis. ${ }^{50,52}$ Metabolism of the antibody denosumab is likely to involve degradation to peptides and amino acids via immunoglobulin clearance pathways and not through hepatic pathways, implying that denosumab pharmacokinetics are unlikely to be affected by hepatic impairment. ${ }^{52}$ Serum concentrations of denosumab decline over a prolonged $\beta$-phase followed by a more rapid elimination phase. ${ }^{53}$ After multiple doses of $120 \mathrm{mg}$ every 4 weeks, the mean elimination half-life was 28 days. ${ }^{51}$ No detectable amounts of denosumab were detected 6 months after a single dose or after multiple subcutaneous $60 \mathrm{mg}$ doses once every 6 months. ${ }^{50,52}$ A population pharmacokinetic meta-analysis of studies in healthy volunteers reported no clinically important effects of age, race, or bodyweight on denosumab pharmacokinetics in patients with cancer. As a result, recommended dosage approved by the Food and Drug Administration (FDA) is not weightdependent. $^{51}$

\section{Clinical use, efficacy, safety, and tolerability of denosumab}

On November 18, 2010, the US FDA approved the use of denosumab for the prevention of SREs in patients with bone metastases from solid tumors, and on September 16, 2011, the FDA approved the use of denosumab as a treatment to increase bone mass in patients at high risk for fracture, including patients on ADT for nonmetastatic prostate cancer. Each indication requires a different dosing and frequency of denosumab administration. As a treatment for the prevention of SREs in bone metastases from solid tumors, denosumab (Xgeva $^{\circledR}$; Amgen, Thousand Oaks, CA) is administered as a $120 \mathrm{mg}$ subcutaneous injection in the upper arm, thigh, or abdomen once every four weeks. As a treatment for increasing bone mass in patients at high risk for fracture, including those undergoing ADT for nonmetastatic prostate cancer, denosumab (Prolia ${ }^{\circledR}$; Amgen) is administered as a $60 \mathrm{mg}$ subcutaneous injection once every 6 months. The use of denosumab for the treatment of osteoporosis is reported elsewhere. ${ }^{54-56}$

Toxicities related to denosumab administration were of sufficient concern that the FDA requested postmarketing surveillance studies. Hypocalcemia was seen in $13 \%$ of patients ( $5 \%$ with grade 3 or higher), with low calcium levels occurring most frequently in the first 6 months after initiation of treatment. ${ }^{9}$ Calcium levels should be repleted prior to initiating denosumab, and patients should be monitored closely, especially during the first few months of treatment. National Osteoporosis Foundation Guidelines call for patients $>50$ years of age being treated with denosumab to consume elemental calcium $1200-1500 \mathrm{mg} /$ day and vitamin D 800-1000 international units/day while being treated with denosumab. ${ }^{57}$ In addition, severe hypophosphatemia was experienced by $15.4 \%$ of patients in a pooled analysis, ${ }^{40}$ and phosphate levels should be monitored and repleted as needed.

Osteonecrosis of the jaw was seen in 5\% of patients on denosumab and in none on placebo in a Phase III trial with 1432 patients with nonmetastatic, castration-resistant prostate cancer. ${ }^{11}$ A second trial involving patients with metastatic disease found a nonsignificant trend toward cumulative increases in osteonecrosis of the jaw (1\% in year 1 and $2 \%$ in year 2). ${ }^{12}$ The majority of patients who developed osteonecrosis of the jaw (79\%) had poor oral hygiene, dental appliances, and/or a recent history of tooth extraction. The median time to development of osteonecrosis of the jaw was 14 months. ${ }^{40}$ Oral examination and preventive dentistry should be performed prior to the initiation of denosumab, and 
patients should be closely monitored for symptoms indicating the development of osteonecrosis of the jaw.

Other uncommon but serious toxicities, including infections, secondary malignancies, and cataracts, have been observed in selected studies. Given RANKL expression on both $\mathrm{T}$ and $\mathrm{B}$ cells, there exists a basis for concern about an increased risk of serious infections and tumor development or progression with denosumab. Several (but not all) studies have found small but significant increases in serious infections in the denosumab arm of their trials including, for example, respiratory infections and cellulitis, rarely requiring hospitalization. ${ }^{58}$ The risk of increased cataract development is being evaluated in a Phase III trial [NCT00925600].

\section{Phase III trials of denosumab for the prevention of SREs}

The safety and efficacy of denosumab were evaluated in a double-blind Phase III trial comparing denosumab with zoledronic acid - the standard of care for delaying SREs in metastatic castration-resistant prostate cancer patients. From May 2006 through October 2009, 1904 men with castrationresistant prostate cancer were enrolled from 342 centers in 39 countries, and were randomized 1:1 to receive denosumab or zoledronic acid. Eligible patients included those with prostate adenocarcinoma who had failed at least one line of hormone therapy (PSA $>0.4 \mu \mathrm{g} / \mathrm{L}$ and rising), and had radiographic evidence of at least one bone metastasis. Additional inclusion criteria were albumin-adjusted calcium levels of 2.0 to $2.9 \mathrm{mmol} / \mathrm{L}$ and Eastern Cooperative Oncology Group performance status $<2$. Exclusion criteria included: prior intravenous treatment with bisphosphonate or current oral bisphosphonate treatment for bone metastases; planned palliative radiation or surgery to bone; a life expectancy of less than 6 months; creatinine clearance $<30 \mathrm{~mL} / \mathrm{min}$; and current or previous osteonecrosis of the jaw. The primary endpoint was time to the first on-study SRE (including spinal cord compression, pathological fracture, radiation to bone, or bone surgery). Denosumab lengthened the time to SRE by $18 \%$ with a between group difference of 3.6 months (20.7 months for those on denosumab, 17.1 months for those on zoledronic acid) (HR $0.82 ; 95 \%$ confidence interval [CI]: $0.71-0.95 ; P=0.0002$ for noninferiority and 0.008 for superiority). At the primary analysis cut-off date, median on-study duration was 12.2 months for patients treated with denosumab and 11.2 months for patients treated with zoledronic acid. ${ }^{12}$ Subgroup analysis found that denosumab had an even greater advantage over zoledronic acid in delaying time to first on-study SRE in patients with no prior SRE (HR 0.80; 95\% CI: 0.67 to $0.95 ; P=0.011$ ) and no or mild pain at baseline (HR $0.77 ; 95 \% \mathrm{CI}$ : 0.63 to 0.95 ; $P=0.014) .^{59}$

Decreases in bone turnover markers were significantly greater for men in the denosumab group (42\% in uNTX/Cr and $65 \%$ in bone-specific alkaline phosphate) demonstrating greater suppression of bone turnover with denosumab. ${ }^{12}$ Further illuminating denosumab's role in the suppression of bone turnover, a meta-analysis of two Phase II studies of denosumab in men and women with bone metastases showed marked suppression of bone resorption markers even in patients who had little biological response to prior bisphosphonate treatment. ${ }^{60}$

Nearly all patients in the Phase III prostate cancer trial of denosumab ( $97 \%$ in both arms) experienced adverse effects, with serious adverse affects recorded for $63 \%$ of men in the denosumab group and $60 \%$ of men in the zoledronic acid group. Hypocalcemia was recorded in twice as many men in the denosumab group as in the zoledronic acid group (13\% versus $6 \% ; P<0.001)$. Osteonecrosis of the jaw occurred in $2 \%$ of men in the denosumab group and in $1 \%$ of men in the zoledronic acid group. ${ }^{12}$

Two other pivotal Phase III studies comparing denosumab and zoledronic acid enrolled 2046 breast cancer patients with bone metastases, and 1776 patients with other solid tumors or myeloma and bone metastases. Inclusion and exclusion criteria were similar to those used in the prostate cancer trial, and patients were randomized $1: 1$ to receive $120 \mathrm{mg}$ denosumab subcutaneously or zoledronic acid. ${ }^{42,45}$ These trials also found denosumab to be superior to zoledronic acid, except in patients with myeloma. When the FDA approved denosumab as a treatment for the prevention of SREs in bone metastases, it included patients with solid tumors, but not those with myeloma.

\section{Phase III trials evaluating treatments for extending bone metastasis-free survival}

Denosumab's effectiveness in extending bone metastasisfree survival was evaluated in a Phase III trial that enrolled 1432 men with castration-resistant prostate cancer who were at high risk of developing bone metastases based on a PSA $\geq 8 \mu \mathrm{g} / \mathrm{L}$ and/or a PSA doubling time $<10$ months. Men in the denosumab arm saw a risk reduction of $15 \%$ and extension of metastasis-free-survival of 4.2 months $(29.5$ versus 25.2 months, $\mathrm{HR}=0.85, P=0.028$ ). Risk of symptomatic bone-metastases was 33\% lower in the denosumab $\operatorname{arm}(\mathrm{HR}=0.67, P=0.01) .{ }^{11}$ 
On February 8, 2012, the FDA Oncologic Drugs Advisory Committee voted 12 to 1 against the approval of denosumab for the treatment of men with castration-resistant prostate cancer who are at high risk of developing bone metastases. The reasoning was based on the modest improvement in metastasis-free survival relative to how frequently patients undergo bone scan imaging in routine clinical practice, and the $5 \%$ incidence of osteonecrosis of the jaw, which correlated with time on the drug, and the absence of a survival benefit. ${ }^{61}$ On April 26, 2012 the FDA issued a letter saying that denosumab did not have a sufficiently favorable riskbenefit profile to be approved for the treatment of men with nonmetastatic castration-resistant prostate cancer. ${ }^{62}$

The study of denosumab in extending metastasis-free survival is the latest in a series of studies of drugs that have shown important benefits in late stage disease that did not confer substantial benefit in earlier stage disease, including clodronate, atrasentan, and zoledronic acid. ${ }^{63-65}$ The consistent inability to meet primary endpoints and/or to gain FDA approval reflects a challenge in treating relatively healthy patients suffering from a slow-growing disease with drugs that have limited effects and cause significant time-dependent cumulative toxicities.

\section{Pharmacoeconomics of denosumab}

Having shown significant clinical advantages over zoledronic acid, denosumab has gained rapid adoption by physicians treating prostate cancer patients with bone metastases. However, at twice the cost per injection of zoledronic acid, the cost effectiveness of denosumab is controversial. One study conducted by a commercial health economics firm found that the higher cost of denosumab led to an incremental cost per quality-adjusted-life-year of US\$1,250,000, well over the US $\$ 50,000$ to US $\$ 100,000$ per quality-adjustedlife-year, which was considered a "good value for a medical intervention." ${ }^{\prime 66}$ A second, more favorable economic evaluation found that the total cost per prostate cancer patient, including drug and nondrug costs for one year of treatment with denosumab was US $\$ 35,431$ versus US $\$ 27,528$ for zoledronic acid. The study also calculated the total incremental cost per SRE avoided with denosumab instead of zoledronic acid was US\$71,027 for 1 year and US\$51,319 for 3 years. ${ }^{67}$

Despite the price difference, most insurers provide reimbursement for either zoledronic acid or denosumab. A few insurers, on the other hand, are questioning not only the cost effectiveness of denosumab, but also the methodology used in determining that denosumab was superior to zoledronic acid. An insurer in the Northwest that covers two million people has decided to pay for denosumab only for patients who are unable to use zoledronic acid or a similar drug, pamidronate. That insurer questioned the evidence of denosumab's superiority, and claimed one clinical study of denosumab in breast cancer patients was "flawed" both because of the metrics used, and because more than half of the patients didn't complete the study. ${ }^{68}$

The difference in cost between the two drugs may be overstated because the cost of administration and the time required of caregivers is lower for the subcutaneously injected denosumab as compared with zoledronic acid, which requires a 15-30 minute infusion, as well as a delay for the laboratory studies of creatinine levels required prior to each infusion.

\section{Conclusion}

Denosumab provides significant improvements for the prevention of SREs in patients with castration-resistant metastatic prostate cancer as compared with the previous standard of care, zoledronic acid. Despite its higher cost versus zoledronic acid, denosumab's superiority in delaying skeletal-related events, its ease of administration, and its availability for patients with renal impairment make it the drug of choice for most physicians in this setting. However, toxicities associated with denosumab administration, especially the increasing incidence of osteonecrosis of the jaw with long-term administration, should be considered in drug selection. Post marketing trials and surveillance studies are being conducted to provide additional information on the frequency of other adverse effects. Zoledronic acid remains a suitable alternative, especially in cases where adequate insurance coverage is not available. When patients are also being treated with docetaxel or cabazitaxel at 3-week intervals, the 4-week dosing interval of denosumab may be extended to 6 weeks. This is based on pharmacokinetic and pharmacodynamic data showing that even when denosumab is given only every 12 weeks, it leads to maintenance of adequate serum concentrations of the drug as well as persistent suppression of markers of bone turnover during the longer dosing interval. ${ }^{69,70} \mathrm{In}$ all cases where denosumab is being administered, vitamin D and calcium should be administered to prevent hypocalcemia.

The role of denosumab in advanced prostate cancer is likely to evolve as other bone-targeting agents show benefit and become available for treatment among different subsets of patients. Combination treatments or other therapeutic 
strategies may emerge that not only reduce bone-related disability, but also improve survival by controlling skeletal metastatic disease progression.

\section{Disclosure}

The authors report no conflict of interest in this work.

\section{References}

1. Jemal A, Bray F, Center MM, Ferlay J, Ward E, Forman D. Global cancer statistics. CA Cancer J Clin. 2011;61(2):69-90.

2. Siegel R, Naishadham D, Jemal A. Cancer statistics. CA Cancer J Clin. 2012;62(1):10-29.

3. de Bono JS, Oudard S, Ozguroglu M, et al; for TROPIC Investigators. Prednisone plus cabazitaxel or mitoxantrone for metastatic castrationresistant prostate cancer progressing after docetaxel treatment: a randomised open-label trial. Lancet. 2010;376(9747):1147-1154.

4. Bubendorf L, Schopfer A, Wagner U, et al. Metastatic patterns of prostate cancer: an autopsy study of 1,589 patients. Hum Pathol. 2000;31(5):578-583.

5. Scher HI, Morris MJ, Basch E, Heller G. End points and outcomes in castration-resistant prostate cancer: from clinical trials to clinical practice. J Clin Oncol. 2011;29(27):3695-3704.

6. Ryan CJ, Smith M, De Bono JS, et al. Interim analysis (IA) results of COU-AA-302, a randomized, phase III study of abiraterone acetate (AA) in chemotherapy-naive patients (pts) with metastatic castration-resistant prostate cancer (mCRPC) [abstract]. J Clin Oncol. 2012;30(Supp1):LBA4518.

7. Parker C, Heinrich D, O'Sullivan J, et al. Overall survival benefit and safety profile of radium-223 chloride, a first-in-class alphapharmaceutical: results from a phase III randomized trial (ALSYMPCA) in patients with castration-resistant prostate cancer (CRPC) with bone metastases [abstract]. J Clin Oncol. 2012;Supp1 5:8.

8. De Bono JS, Fizazi K, Saad F, et al. Primary, secondary and quality-oflife endpoint results from the phase III AFFIRM study of MDV3100, an androgen receptor signaling inhibitor [abstract]. J Clin Oncol. 2012;30(Suppl):4519.

9. Smith MR, Kabbinavar F, Saad F, et al. Natural history of rising serum prostate-specific antigen in men with castrate nonmetastatic prostate cancer. J Clin Oncol. 2005;23(13):2918-2925.

10. Smith MR, Cook R, Lee KA, Nelson JB. Disease and host characteristics as predictors of time to first bone metastasis and death in men with progressive castration-resistant nonmetastatic prostate cancer. Cancer. 2011;117(10):2077-2085.

11. Smith MR, Saad F, Coleman R, et al. Denosumab and bone-metastasisfree survival in men with castration-resistant prostate cancer: results of a phase 3, randomised, placebo-controlled trial. Lancet. 2012; 379(9810):39-46.

12. Fizazi K, Carducci M, Smith M, et al. Denosumab versus zoledronic acid for treatment of bone metastases in men with castration-resistant prostate cancer: a randomised, double-blind study. Lancet. 2011;377(9768): 813-822.

13. Roodman GD. Mechanisms of bone metastasis. $N$ Engl J Med. 2004;350(16):1655-1664.

14. Venkitaraman R, Sohaib SA, Barbachano Y, et al. Detection of occult spinal cord compression with magnetic resonance imaging of the spine. Clin Oncol (R Coll Radiol). 2007;19(7):528-531.

15. Even-Sapir E, Metser U, Mishani E, Lievshitz G, Lerman H, Leibovitch I. The detection of bone metastases in patients with highrisk prostate cancer: 99mTc-MDP Planar bone scintigraphy, singleand multi-field-of-view SPECT, 18F-fluoride PET, and 18F-fluoride PET/CT. J Nucl Med. 2006;47(2):287-297.

16. Blair HC, Teitelbaum SL, Ghiselli R, Gluck S. Osteoblastic bone resorption by a polarized vacuolar proton pump. Science. 1989;245(4920): $855-857$.
17. Brown JE, Cook RJ, Major P, et al. Bone turnover markers as predictors of skeletal complications in prostate cancer, lung cancer, and other solid tumors. J Natl Cancer Inst. 2005;97(1):59-69.

18. Smith MR, Saad F, Egerdie B, et al. Denosumab and changes in bone turnover markers during androgen deprivation therapy for prostate cancer. J Bone Miner Res. 2011;26(12):2827-2833.

19. Paller CJ, Shiels MS, Rohrmann S, et al. Relationship of sex steroid hormones with bone mineral density (BMD) in a nationally representative sample of men. Clin Endocrinol (Oxf). 2009;70(1): 26-34.

20. Gennari L, Nuti R, Bilezikian JP. Aromatase activity and bone homeostasis in men. J Clin Endocrinol Metab. 2004;89(12):5898-5907.

21. Smith MR, McGovern FJ, Zietman AL, et al. Pamidronate to prevent bone loss during androgen-deprivation therapy for prostate cancer. N Engl J Med. 2001;345(13):948-955.

22. Shahinian VB, Kuo YF, Freeman JL, Goodwin JS. Risk of fracture after androgen deprivation for prostate cancer. $N$ Engl J Med. 2005;352(2): 154-164.

23. Saylor PJ, Morton RA, Hancock ML, Barnette KG, Steiner MS, Smith MR. Factors associated with vertebral fractures in men treated with androgen deprivation therapy for prostate cancer. J Urol. 2011; 186(2):482-486.

24. Alibhai SM, Duong-Hua M, Cheung AM, et al. Fracture types and risk factors in men with prostate cancer on androgen deprivation therapy: a matched cohort study of 19,079 men. J Urol. 2010;184(3): 918-923.

25. Jones CU, Hunt D, McGowan DG, et al. Radiotherapy and short-term androgen deprivation for localized prostate cancer. $N$ Engl J Med. 2011;365(2):107-118.

26. Bolla M, de Reijke TM, Van Tienhoven G, et al; for EORTC Radiation Oncology Group and Genito-Urinary Tract Cancer Group. Duration of androgen suppression in the treatment of prostate cancer. NEngl J Med. 2009;360(24):2516-2527.

27. Messing EM, Manola J, Sarosdy M, Wilding G, Crawford ED, Trump D. Immediate hormonal therapy compared with observation after radical prostatectomy and pelvic lymphadenectomy in men with node-positive prostate cancer. $N$ Engl J Med. 1999;341(24):1781-1788.

28. Tannock IF, de Wit R, Berry WR, et al; for TAX 327 Investigators. Docetaxel plus prednisone or mitoxantrone plus prednisone for advanced prostate cancer. $N$ Engl J Med. 2004;351(15):1502-1512.

29. de Bono JS, Logothetis CJ, Molina A, et al; for COU-AA-301 Investigators. Abiraterone and increased survival in metastatic prostate cancer. N Engl J Med. 2011;364(21):1995-2005.

30. Carducci MA, Saad F, Abrahamsson PA, et al; for Atrasentan Phase III Study Group Institutions. A phase 3 randomized controlled trial of the efficacy and safety of atrasentan in men with metastatic hormonerefractory prostate cancer. Cancer. 2007;110(9):1959-1966.

31. Nelson JB, Fizazi K, Miller K, et al. Phase III study of the efficacy and safety of zibotentan (ZD4054) in patients with bone metastatic castration resistant prostate cancer (CRPC) [abstract]. J Clin Oncol. 2011;29(Suppl 7):117.

32. Yu EY, Massard C, Gross ME, et al. Once-daily dasatinib: expansion of phase II study evaluating safety and efficacy of dasatinib in patients with metastatic castration-resistant prostate cancer. Urology. 2011;77(5):1166-1171.

33. Sartor O. Overview of samarium sm 153 lexidronam in the treatment of painful metastatic bone disease. Rev Urol. 2004;6 Suppl 10: S3-S12.

34. Dearnaley DP, Mason MD, Parmar MK, Sanders K, Sydes MR. Adjuvant therapy with oral sodium clodronate in locally advanced and metastatic prostate cancer: long-term overall survival results from the MRC PR04 and PR05 randomised controlled trials. Lancet Oncol. 2009;10(9):872-876.

35. Michaelson MD, Kaufman DS, Lee H, et al. Randomized controlled trial of annual zoledronic acid to prevent gonadotropin-releasing hormone agonist-induced bone loss in men with prostate cancer. J Clin Oncol. 2007;25(9):1038-1042. 
36. Greenspan SL, Nelson JB, Trump DL, Resnick NM. Effect of onceweekly oral alendronate on bone loss in men receiving androgen deprivation therapy for prostate cancer: a randomized trial. Ann Intern Med. 2007;146(6):416-424.

37. Small EJ, Smith MR, Seaman JJ, Petrone S, Kowalski MO. Combined analysis of two multicenter, randomized, placebo-controlled studies of pamidronate disodium for the palliation of bone pain in men with metastatic prostate cancer. J Clin Oncol. 2003;21(23): 4277-4284.

38. Saad F, Gleason DM, Murray R, et al; for Zoledronic Acid Prostate Cancer Study Group. A randomized, placebo-controlled trial of zoledronic acid in patients with hormone-refractory metastatic prostate carcinoma. $J$ Natl Cancer Inst. 2002;94(19):1458-1468.

39. Kostenuik PJ, Nguyen HQ, McCabe J, et al. Denosumab, a fully human monoclonal antibody to RANKL, inhibits bone resorption and increases BMD in knock-in mice that express chimeric (murine/human) RANKL. J Bone Miner Res. 2009;24(2):182-195.

40. Amgen. XGEVA (denosumab) Injection, for Subcutaneous Use: US Prescribing Information [document on the Internet]. Thousand Oaks, CA: Amgen; [updated 2011]. Available from: http://pi.amgen.com/ united_states/xgeva/xgeva_pi.pdf. Accessed on May 2, 2012.

41. Fizazi K, Lipton A, Mariette X, et al. Randomized phase II trial of denosumab in patients with bone metastases from prostate cancer, breast cancer, or other neoplasms after intravenous bisphosphonates. J Clin Oncol. 2009;27(10):1564-1571.

42. Henry DH, Costa L, Goldwasser F, et al. Randomized, double-blind study of denosumab versus zoledronic acid in the treatment of bone metastases in patients with advanced cancer (excluding breast and prostate cancer) or multiple myeloma. J Clin Oncol. 2011;29(9): 1125-1132.

43. Lewiecki EM, Bilezikian JP. Denosumab for the treatment of osteoporosis and cancer-related conditions. Clin Pharmacol Ther. 2012;91(1):123-133.

44. Seeman E, Delmas PD, Hanley DA, et al. Microarchitectural deterioration of cortical and trabecular bone: differing effects of denosumab and alendronate. J Bone Miner Res. 2010;25(8):1886-1894.

45. Stopeck AT, Lipton A, Body JJ, et al. Denosumab compared with zoledronic acid for the treatment of bone metastases in patients with advanced breast cancer: a randomized, double-blind study. J Clin Oncol 2010;28(35):5132-5139.

46. Lipton A, Steger GG, Figueroa J, et al. Randomized active-controlled phase II study of denosumab efficacy and safety in patients with breast cancer-related bone metastases. J Clin Oncol. 2007;25(28): 4431-4437.

47. Body JJ, Facon T, Coleman RE, et al. A study of the biological receptor activator of nuclear factor-kappaB ligand inhibitor, denosumab, in patients with multiple myeloma or bone metastases from breast cancer. Clin Cancer Res. 2006;12(4):1221-1228.

48. Coleman RE. Risks and benefits of bisphosphonates. $\mathrm{Br} J$ Cancer. 2008;98(11):1736-1740.

49. Lipton A, Steger GG, Figueroa J, et al. Extended efficacy and safety of denosumab in breast cancer patients with bone metastases not receiving prior bisphosphonate therapy. Clin Cancer Res. 2008;14(20): 6690-6696.

50. Amgen Incorporated. Prolia ${ }^{\mathrm{TM}}$ (Denosumab) injection, for subcutaneous use: US prescribing information [online]. Thousand Oaks, CA: Amgen Inc; 2010. http://pi.amgen.com/united_states/prolia/prolia_pi.pdf. Accessed May 1, 2012.

51. Amgen Incorporated. XGEVA (denosumab) injection, for subcutaneous use: US prescribing information [online]. Thousand Oaks, CA: Amgen Inc; 2010. http://pi.amgen.com/united_states/xgeva/xgeva_pi.pdf. Accessed May 1, 2012

52. Amgen Incorporated. Prolia $60 \mathrm{mg}$ Solution for Injection in a Prefilled Syringe: EU Summary of Product Characteristics. Breda, The Netherlands: Amgen Europe BV; 2010.
53. Bekker PJ, Holloway DL, Rasmussen AS, et al. A single-dose placebo-controlled study of AMG 162, a fully human monoclonal antibody to RANKL, in postmenopausal women. $J$ Bone Miner Res. 2004;19(7):1059-1066.

54. Cummings SR, San Martin J, McClung MR, et al; for FREEDOM Trial. Denosumab for prevention of fractures in postmenopausal women with osteoporosis. N Engl J Med. 2009;361(8):756-765.

55. Smith MR, Egerdie B, Hernandez Toriz N, et al; for Denosumab HALT Prostate Cancer Study Group. Denosumab in men receiving androgen-deprivation therapy for prostate cancer. $N$ Engl J Med. 2009;361(8):745-755

56. Adler RA, Gill RS. Clinical utility of denosumab for treatment of bone loss in men and women. Clin Interv Aging. 2011;6:119-124.

57. National Osteoperosis Foundation. Clinician's Guide to Prevention and Treatment of Osteoporosis. Washington, DC: National Osteoporosis Foundation; 2010.

58. Rothstein A. Denosumab Safety: Division of Reproductive and Urologic Products, Center of Drug Evaluation and Research at the Food and Drug Administration [document on the Internet]; [updated 2009]. Available from: http://courses.washington.edu/bonephys/denosumab/ Rothstein\%20FDA\%20deno\%20safety.pdf. Accessed on May 2, 2012.

59. Shore N, Smith R, Jievaltas M, et al. Effect of denosumab versus zoledronic acid in patients with castrate-resistant prostate cancer and bone metastases: subgroup analyses by prior SRE and baseline pain. J Clin Oncol. 2011;29(Suppl):4533.

60. Body JJ, Lipton A, Gralow J, et al. Effects of denosumab in patients with bone metastases with and without previous bisphosphonate exposure. J Bone Miner Res. 2010;25(3):440-446.

61. Hale C. ODAC votes to nix Amgen's drug Xgeva for proposed prostate cancer indication. Cancer Lett. 2012;38(7):1.

62. Goldberg P. Xgeva doesn't meet the bar in controversial indication. Cancer Lett. 2012;38(18):8.

63. Mason MD, Sydes MR, Glaholm J, et al; for Medical Research Council PR04 Collaborators. Oral sodium clodronate for nonmetastatic prostate cancer - results of a randomized double-blind placebo-controlled trial: Medical Research Council PR04 (ISRCTN61384873). J Natl Cancer Inst. 2007;99(10):765-776.

64. Nelson JB, Love W, Chin JL, et al; for Atrasentan Phase 3 Study Group. Phase 3, randomized, controlled trial of atrasentan in patients with nonmetastatic, hormone-refractory prostate cancer. Cancer. 2008;113(9):2478-2487.

65. Lee RJ, Smith MR. Osteoclast-targeted therapy for metastatic prostate cancer. Therapy. 2008;5(1):63-72.

66. Snedecor SJ, Carter JA, Kaura S, Botteman M. Cost-effectiveness of zoledronic acid (ZOL) versus denosumab (Dmab) in prevention of skeletal-related events (SREs) in castration-resistant prostate cancer metastatic to the bone (mCRPC). J Clin Oncol. 2011;29(Suppl):4581.

67. Xie J, Namjoshi M, Wu EQ, et al. Economic evaluation of denosumab compared with zoledronic acid in hormone-refractory prostate cancer patients with bone metastases. J Manag Care Pharm. 2011;17(8):621-643.

68. Gyrta T. Amgen's Xgeva hits resistance over cost-benefit debate [article on the Internet]. New York: Dow Jones News Service [updated April 5, 2011; cited February 18, 2012]. Available from: http://www. advfn.com/news_Amgens-Xgeva-Hits-Resistance-Over-Cost-BenefitDebate_47174840.html. Accessed February 18, 2012. May 2,2012.

69. Gibiansky L, Sutjandra L, Doshi S, et al. Population pharmacokinetic analysis of denosumab in patients with bone metastases from solid tumours. Clin Pharmacokinet. 2012;51(4):247-260.

70. EMC. XGEVA pharmacological properties [homepage on the Internet]. Cambridge: Medicines Compendium; [updated 2012]. Available from: http://www.medicines.org.uk/emc/medicine/24755/SPC/xgeva/. Accessed on May 2, 2012. 


\section{Publish your work in this journal}

Clinical Interventions in Aging is an international, peer-reviewed journal focusing on evidence-based reports on the value or lack thereof of treatments intended to prevent or delay the onset of maladaptive correlates of aging in human beings. This journal is indexed on PubMed Central, MedLine, the American Chemical Society's 'Chemical Abstracts Ser-

vice' (CAS), Scopus and the Elsevier Bibliographic databases. The manuscript management system is completely online and includes a very quick and fair peer-review system, which is all easy to use. Visit $\mathrm{http}: / /$ www.dovepress.com/testimonials.php to read real quotes from published authors.

Submit your manuscript here: http://www.dovepress.com/clinical-interventions-in-aging-journal 